\title{
Ekstraksi Oleoresin Lada Hitam Secara Maserasi Menggunakan Metode Permukaan Respon
}

\author{
Liya Fitriyana $^{* 1}$, Irmayanti ${ }^{2}$, Putri Meutia Sari ${ }^{3}$, Virna Muhardina ${ }^{4}$ \\ 1,2,3,4 Staf Pengajar Prodi Teknologi Industri Pertanian, Fakultas Teknologi Pertanian \\ Universitas Serambi Mekkah, Batoh-Banda Aceh \\ *Koresponden email: liyafitriyana80@gmail.com
}

Masuk: 4 Desember 2017

Diterima: 8 Desember 2017

\begin{abstract}
Purpose of this study is to determine the optimum conditions of extraction using conventional methods (maceration) and ultrasonic methods by using response surface method (RSM). The variables used in this study is the ratio of solvent with black pepper, temperature and time of extraction. Solvents used in this study is $99 \%$ ethanol. The bigest yield of oleoresin using maceration method was $4.42 \%$ with a ratio of solvent and black pepper for $1: 4 \mathrm{~g} / \mathrm{ml}$ and extraction time of 4.68 hours. GC-MS test showed that the piperine contained in oleoresin extracted by using maceration are respectively $69.92 \%$ FT-IR test showed that oleoresin extracted using maceration have the same bound that same as piperine bound. Organoleptic test showed that oleoresin produced by using maceration meet the requirement of ISO standards 06-2388-1998 (dark brown color, pepper smell and thick paste form).
\end{abstract}

Keywords : Black pepper, Maceration, Oleoresin, Respon surface Method (RSM)

\begin{abstract}
Abstrak. Penelitian ini bertujuan untuk mengetahui kondisi optimum dari ektraksi dengan menggunakan metode maserasi dengan menggunakan response surface method (RSM). Variabel yang digunakan pada penelitian ini adalah rasio perbandingan pelarut dengan lada hitam, temperatur, dan waktu ekstraksi. Pelarut yang digunakan dalam penelitian ini adalah ethanol $99 \%$. Rendemen oleoresin terbesar dengan menggunakan metode maserasi adalah 4,42\% dengan rasio perbandingan pelarut dan lada hitam sebesar 1:4 gr/ml dan waktu ekstraksi 4,68 jam. Berdasarkan uji GC-MS diketahui bahwa kandungan piperin yang terdapat di dalam oleoresin yang diekstrak menggunakan metode maserasi adalah 69,92\%. Untuk uji gugus fungsi dengan menggunakan FT-IR diperoleh bahwa oleoresin yang diekstrak dengan menggunakan metode maserasi memiliki gugus yang sama dan mengandung piperin. Dari hasil uji organoleptik diketahui bahwa oleoresin yang dihasilkan memenuhi standar SNI 06-2388-1998 yaitu berwarna coklat pekat, beraroma khas lada dan berbentuk pasta kental.
\end{abstract}

Kata kunci : Lada Hitam, Maserasi, Oleoresin, Response Surface Method (RSM)

\section{Pendahuluan}

Indonesia menempati urutan ketiga di dunia sebagai penghasil lada, setelah Malaysia dan India. Tanaman ini tumbuh subur dan telah banyak berkembang di Bangka, Lampung, Kalimantan Barat, Kalimantan Timur dan Aceh (Nuryawan dkk., 2007).

Tanaman lada juga telah dikenal sejak lama dan bisa tumbuh dengan subur. Lada termasuk jenis tanaman rempah-rempah yang penting dan dikenal luas oleh seluruh lapisan masyarakat. Tumbuhan lada berasal dari daerah India Selatan. Tumbuhan ini dapat tumbuh hingga ketinggian hingga $50-60 \mathrm{~cm}$. Lada hitam sebenarnya berasal dari tumbuhan yang sama, yang membedakan hanyalah cara penanganan buah setelah panen. Lada hitam didapat jika buah lada dipanen sebelum matang, langkah selanjutnya, kemudian dikeringkan dibawah sinar matahari hingga warnanya hitam. Berikutnya buah lada tersebut direndam dalam air sampai kulitnya terpisah dari buah. Sedangkan pembuatan lada putih lebih sederhana, buah lada dipetik sampai keadaan buah matang dipohon. Kemudian dicuci menggunakan air yang mengalir (Bagheri $\mathrm{H}$, dkk, 2014).

Lada hitam terkenal karena mempunyai sifat aromatik dan memiliki kandungan zat anti 


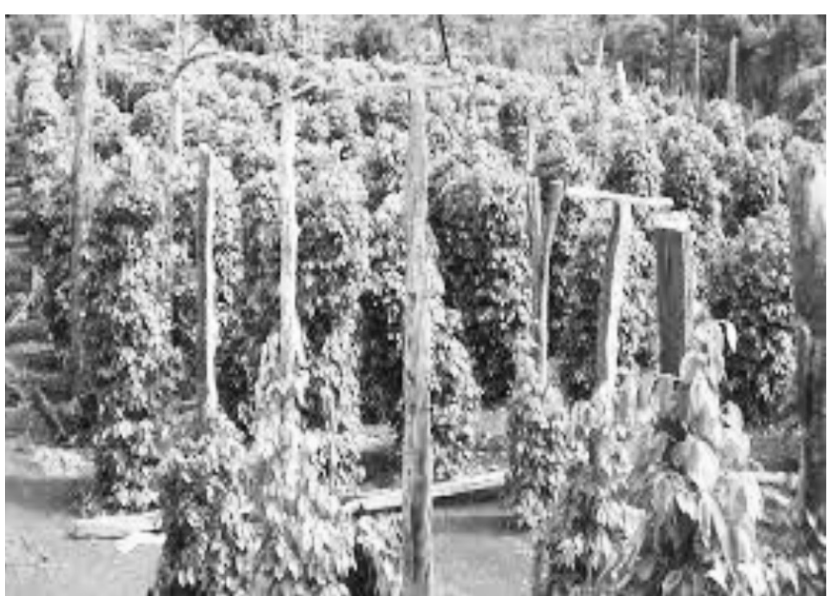

Gambar 1. Pohon lada

Sumber: Anwar (1994)

oksidan, anti mikroba dan karminatif (untuk mengeluarkan gas dari saluran pencernaan). Lada hitam mengandung banyak manfaat. Baik untuk industri makanan maupun untuk obat-obatan. Manfaat dari segi obat-obatan diantaranya adalah dapat digunakan untuk obat pereda rasa sakit, diantaranya sakit radang sendi, lemah/lesu, influenza, obat saraf, anti bakteri, perangsang (stimulus), obat pencernaan dan penawar racun (Bagheri H, dkk., 2014). Oleoresin merupakan salah satu komponen non volatil terbesar yang terkandung didalam lada hitam (Hartuti, 2011).

Tanaman lada telah dikenal sejak lama dan bisa tumbuh dengan subur. Dapat tumbuh hingga mencapai ketinggian hingga 50 sampai $60 \mathrm{~cm}$, termasuk tumbuhan semak atau perdu yang tumbuh memanjat dengan akar-akar pelekat dan

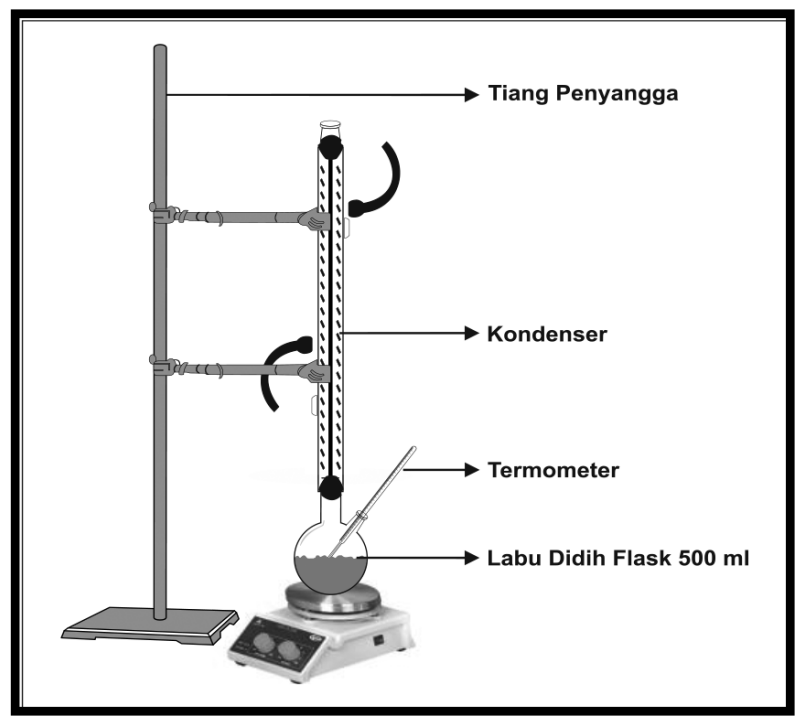

Gambar 2. Sketsa rangkaian unit ekstraksi maserasi digolongkan kedalam jenis tanaman rempahrempah. Lada dikenal luas oleh seluruh lapisan masyarakat. Tumbuhan lada juga dikenal dengan dengan beberapa nama. Diantaranya adalah piper, lada, merica, dan sakang. Tanaman lada dapat dilihat pada Gambar 1.

Buah merupakan hasil produksi utama dari tanaman lada. Dalam taksonomi tumbuhan, kedudukan tanaman lada dapat diklasifikasikan (Nurbaiti dkk., 2007). Ciri dari buah lada adalah dari bentuk dan warna buahnya, yaitu: buah lada berbentuk bulat, berbiji keras dan mempunyai kulit buah yang lunak. Jika buah sudah masak berwarna merah, terdapat lendir dengan rasa manis. Setelah dikeringkan, lada berubah warna menjadi berwarna hitam dan mempunyai lapisan kulit yang keras. Dalam kulit tersebut terdapat biji-biji yang merupakan produk dari lada, bijibiji ini juga mempunyai lapisan kulit yang keras.

Oleoresin mempunyai karakteristik rasa dan aroma yang sama dengan rempah aslinya. Perkembangan dunia disegala bidang dan semakin meningkatnya tuntutan efisiensi menyebabkan penggunaan oleoresin merupakan salah satu usaha yang perlu dikembangkan. Potensi bahan baku oleoresin berupa rempahrempah yang cukup melimpah didalam negeri memungkinkannya dikembangkan industri oleoresin di Indonesia, terutama dalam rangka pemenuhan kebutuhan dunia dan memajukan ekspor non migas (Abubakar dkk., 2007).

Oleoresin merupakan campuran kompleks yang diperoleh dengan cara ekstraksi, biasanya oleoresin dalam bentuk cairan kental, pasta dan padat (Koswara, 1995). Satu $\mathrm{kg}$ oleoresin lada hitam dapat menggantikan pemakaian $10 \mathrm{~kg}$ butir lada hitam (Risfaheri, 2012). Biasanya untuk menghasilkan oleoresin dilakukan dengan ekstraksi konvensional secara maserasi. Sulhatun dkk (2014) telah melakukan penelitian dengan lada hitam sebagai bahan baku dalam pembuatan oleoresin dengan cara ekstraksi secara konvensional. Dan menghasilkan bahwa jenis pelarut dan waktu ekstraksi pada pembuatan oleoresin lada hitam berpengaruh terhadap rendemen oleoresin.

\section{Metodologi Penelitian}

\subsection{Bahan dan Alat}

Bahan yang digunakan adalah lada hitam 
Tabel 1. Rendemen oleoresin lada hitam hasil dari ekstraksi oleroesin menggunakan metode maserasi

\begin{tabular}{ccccc}
\hline & \multicolumn{2}{c}{ Nilai level Variabel X } & \multicolumn{2}{c}{ Rendemen (\%) } \\
\cline { 2 - 5 } Run & $X_{1}$ & $X_{2}$ & Data & Prediksi \\
& Rasio bahan \& pelarut & Waktu (jam) & & 4,14 \\
& $1: 5$ & 4 & 3,76 \\
2 & $1: 4$ & 3 & 2,99 & 3,13 \\
3 & $1: 4$ & 3 & 2,99 & 3,13 \\
4 & $1: 3$ & 4 & 3,6 & 2,87 \\
5 & $1: 4$ & 3 & 2,99 & 3,13 \\
6 & $1: 4$ & 3 & 2,99 & 3,13 \\
7 & $1: 2,32$ & 3 & 1,98 & 2,38 \\
8 & $1: 4$ & 1.32 & 3,11 & 2,83 \\
9 & $1: 5,68$ & 3 & 3,86 & 3,88 \\
10 & $1: 4$ & 3 & 2,99 & 3,13 \\
11 & $1: 3$ & 2 & 2,69 & 2,51 \\
12 & $1: 4$ & 4,68 & 4,42 & 3,44 \\
13 & $1: 5$ & 2 & 3,3 & 3,40 \\
\hline
\end{tabular}

Tabel 2. Model statistik dari ekstrasksi oleoresin dengan menggunakan metode maserasi

\begin{tabular}{cccccc}
\hline $\begin{array}{c}\text { Model } \\
\text { Source }\end{array}$ & $\begin{array}{c}\text { Std } \\
\text { Dev }\end{array}$ & R-squared & $\begin{array}{c}\text { Adjusted } \\
\text { R-squared }\end{array}$ & $\begin{array}{c}\text { Predicted } \\
\text { R-squared }\end{array}$ & Press \\
\hline Linear & 0,34 & 0,6561 & 0,5873 & 0,2944 & 2,41 (disarankan) \\
2F1 & 0,36 & 0,6564 & 0,5419 & $-0,2654$ & 4,32 \\
Quadratic & 0,39 & 0,6837 & 0,4577 & $-1,3841$ & 8,15 \\
\hline
\end{tabular}

(Piper nigrum) yang berasal dari pasar rakyat Peunayong Banda Aceh, etanol 99\%, aquades serta kertas saring. Alat yang digunakan adalah, pompa vakum dan evaporator, gelas beaker, gelas ukur, shaker, saringan, corong pemisah.

\subsection{Waktu dan Tempat Penelitian}

Penelitian ini dilakukan selama 2 (dua) bulan guna untuk mendapatkan hasil sesuai dengan target yang diinginkan. Pelaksanaan penelitian akan dilakukan di Laboratorium Teknik Reaksi dan Katalis Jurusan Teknik Kimia, Fakultas Teknik, Universitas Syiah Kuala

\subsection{Metode}

Penelitian ini menggunakan central composite design (CCD) tiga faktor. Yang termasuk dalam metode permukaan respons untuk melihat kondisi optimum pada pengaruh perlakuan terhadap rasio lada hitam terhadap pelarut etanol, temperatur ekstraksi dan waktu ekstraksi terhadap rendemen oleoresin lada hitam. Harga $\alpha$ untuk desain rotatable adalah:

$\alpha=F^{1 / 4}$
Dimana $\mathbf{F}=\mathbf{2}^{\mathbf{k}}$, dimana $\mathrm{k}$ merupakan jumlah variabel (Hartuti, 2011). Dalam percobaan ini menggunakan tiga variabel. Maka nilai $\mathrm{F}$ sama dengan $2^{3}=8$. Yang berarti delapan alternatif nomor, sehingga sesuai Persamaan (1) diperoleh $\boldsymbol{\alpha}=\mathbf{8}^{\mathbf{1 / 4}}=1,682$ dan untuk nilai $\pm 1,682$ termasuk nilai yang digunakan dalam pengkodean.

Proses Ekstraksi Oleoresin lada hitam menggunakan metode maserasi. Penelitian dilakukan dengan menggunakan metode permukaan respon (RSM). berdasarkan desain yang telah dilakukan, Ekstraksi oleoresin dengan menggunakan maserasi menghasilkan 13 run Langkah pertama untuk maserasi adalah sebanyak 100 g lada hitam dimasukkan ke dalam erlenmeyer kemudian ditambahkan pelarut dan didiamkan selama beberapa waktu berdasarkan dengan run penelitian yang dihasilkan menggunakan model CCD. Hasil ekstraksi kemudian dipisahkan dengan menggunakan vacum evaporator. Setelah diperoleh oleoresinnya kemudian diukur rendemen (\%), kemudian diuji GC-MS, FT-IR, dan organoleptik.

Desain analisa data yang digunakan adalah Central Composite Design (CCD) dan 
menggunakan aplikasi Design Expert Version 6.06 dengan batasan level high (+), low (-), dan middle (0).

Tahapan Ekstraksi Oleoresi Lada Hitam secara Maserasi, Ekstrak oleoresin lada hitam dilakukan secara maserasi adalah dengan cara menimbang lada hitam yang sudah dihancurkan dengan ukuran 40 mesh sebanyak 100 gram, kemudian ditambahkan pelarut etanol dengan perbandingan antara bahan dan pelarut sesuai dengan Tabel 1. Kemudian didiamkan dan direndam sesuai dengan waktu yang tertera juga pada Tabel 1, pada suhu $60^{\circ} \mathrm{C}$. Kemudian dilakukan penyaringan. Filtrat yang dihasilkan diuapkan pelarutnya menggunakan evaporator dengan pengurangan tekanan sampai dihasilkan ekstrak kental. Skema rangkaian unit ekstraksi maserasi ditunjukkan pada Gambar 2.

\subsection{Analisa Data}

Parameteryang diuji dalam penelitian ini adalah rendemen oleoresin (\%), Gass CromatographMass Spectrometry (GC-MS), Fourier Trasform Infra Red(FT-IR) dan organoleptik.

\section{Hasil dan Pembahasan}

\subsection{Central Composite Design (CCD)}

CCD menghasilkan prediksi dari kondisi optimum dari proses ekstraksi oleoresin dengan menggunakan metode maserasi yang dipengaruhi oleh faktor-faktor yang ditentukan oleh variabel tetap.Gambar 2. Sketsa rangkaian unit ekstraksi maserasi

\subsection{Analisis Metode Permukaan Respon \\ Terhadap Rendemen Oleoresin Lada Hitam Dengan Menggunakan Metode Maserasi}

Model linier dianalisa dengan menggunakan plot tiga dimensi dan plot kontur. Plot tiga dimensi diperoleh dari memplot respon persen rendemen oleoresin lada hitam pada sumbu $\mathrm{Y}_{1}$ terhadap $\mathrm{X}$ (rasio perbandingan pelarut dan lada hitam, dan waktu). Setiap plot menunjukkan pengaruh dua variabel dalam kisaran yang ditentukan. Setiap plot menujukkan pengaruh dua variabel dalam kisaran yang ditentukan terhadap variabel lain yang dibuat dalam kondisi tetap. Bentuk plot kontur menunjukkan karakteristik dan besarnya pengaruh interaksi antar variabel terhadap respon.

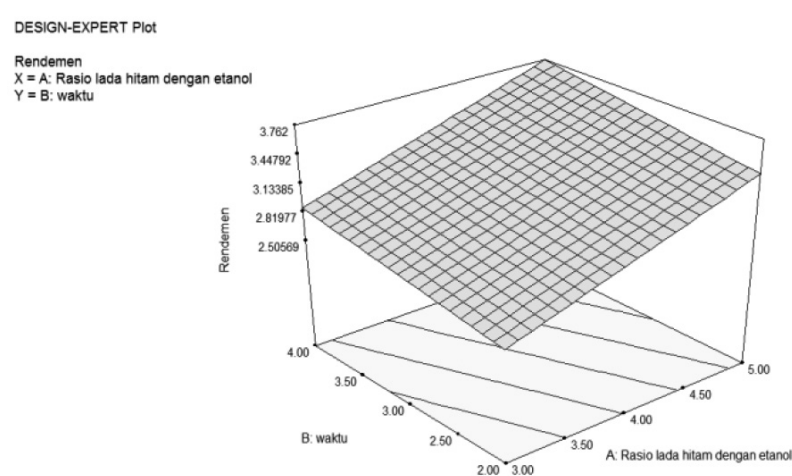

Gambar 3. Pengaruh rasio pelarut:lada hitam dan waktu ekstraksi terhadap rendemen oleoresin lada hitam menggunakan ekstraksi maserasi

Hubungan antara kedua variabel independen terhadap respon diperlihatkan pada Gambar 3.

Berdasarkan Gambar 3, diketahui bahwa rendemen oleoresin lada hitam dengan menggunakan metode maserasi meningkat seiring dengan bertambahnya rasio pelarut dan lada hitam. Lamanya waktu ekstrasi, perbandingan rasio pelarut dengan lada hitam sangat mempengaruhi hasil rendemen yang didapat. Secara umum, semakin lama waktu ekstraksi, maka rendemen yang didapatkan juga semakin banyak. Hal ini disebabkan semakin lama waktu ekstraksi akan memberikan kesempatan kontak antara pelarut dengan bahan yang semakin besar. Kelarutan bahan akan terus meningkat seiring dengan semakin bertambahnya waktu ekstraksi hingga timbulnya kejenuhan pada pelarut (Ketaren dan Suastawa, 1995). Total berat massa yang digunakan dalam tiap rasio adalah sama yaitu sebesar 100 gram. Sehingga pada rasio 1:3 , 1:4 dan 1:5 jumlah bubuk lada hitam yang digunakan semakin sedikit dan pelarut yang digunakan semakin banyak. Banyaknya jumlah bahan baku dan pelarut yang digunakan sangat mempengaruhi rendemen yang dihasilkan, semakin banyak bahan baku dan pelarut yang digunakan maka semakin besar rendemen yang dihasilkan. Kenaikan suhu akan menyebabkan gerakan molekul etanol sebagai pelarut semakin cepat dan acak. Selain itu, kenaikan suhu juga dapat menyebabkan poripori padatan mengembang sehingga memudahkan etanol sebagai pelarut untuk masuk kedalam poripori padatan bahan dan melarutkan oleoresin.

Penelitian lainnya yang dilakukan oleh Singh dkk (2013) mengenai potensi dari ekstraksi 
oleoresin lada (piper ningrum L) menyatakan bahwa ekstraksi dengan waktu yang semakin lama menyebabkan rendemen oleoresin yang dihasilkan semakin banyak. Selain waktu ekstraksi variabel lain seperti rasio perbandingan antara pelarut dan lada hitam, temperatur ekstraksi, dan jenis pelarut juga mempengaruhi rendemen oleoresin yang dihasilkan.

\section{.3.3 Uji Gugus Fungsi menggunakan FT-IR.}

Gugus fungsi dari oleoresin diuji menggunakan FT-IR dengan melihat panjang gelombang dari komponen yang dimiliki oleh sampel. Hasil analisis gugus fungsi dapat dilihat pada Tabel 3.

Dari hasil uji FT-IR tersebut dan perbandingan dari referensi yang ada dapat dilihat bahwa oleoresin yang dihasilkan mengandung piperin.

\subsection{Uji Komposisi Oleoresin menggunakan Gass Cromatograph-Mass Spectrometry (GC-MS)}

Gass Cromatograph-Mass Spectrometry (GCMS) merupakan metode yang digunakan untuk menentukan komposisi dan juga persentasi dari komponen yang terdapat di dalam bahan. Komponen yang paling berpengaruh dalam menentukan kualitas oleoresin adalah piperin, semakin tinggi nilai piperine yang terkandung didalam oleoresin maka kualitasnya juga semakin baik. Nilai persentase piperine yang terdapat didalam oleoresi yang dihasilkan berkisar dari 59-62\%. Dari hasil uji

Tabel 3. Hasil uji FTIR untuk masing-masing sampel oleoresin

\begin{tabular}{ccc}
\hline & \multicolumn{2}{c}{$\begin{array}{c}\text { Panjang Gelombang } \\
\left(\mathrm{cm}^{-1}\right)\end{array}$} \\
\cline { 2 - 3 } Jenis gugus fungsi & maserasi & Referensi \\
\hline Gugus C-H aromatic & 3267 & $>3000^{*}$ \\
Gugus C-H alifatik & 2926 & $2925 *$ \\
$\quad$ Gugus $-\mathrm{CO}-\mathrm{N}$ & 1770 & $1700 *$ \\
$\begin{array}{c}\text { Gugus -O-CH } \\
\text { simetris }\end{array}$ & 1249 & $1230 *$ \\
$\begin{array}{c}\text { Gugus -O-CH } \\
\text { asimetris }\end{array}$ & 1136 & $1134 *$ \\
$\begin{array}{c}\text { gugus }>\mathrm{N}-\mathrm{C}=\mathrm{O} \\
\text { (alifatik) }\end{array}$ & 1614 & $1610 *$ \\
Gugus -C-H & 1037 & $1000 *$ \\
\hline
\end{tabular}

Sumber: ** Saha dkk (2013)

* Baranska dkk (2009)
Tabel 4. Hasil Uji organoleptik dari oleoresin lada hitam

\begin{tabular}{cccc}
\hline Oleoresin & Warna & Aroma & Bentuk \\
\hline \multirow{3}{*}{ Maserasi } & $\begin{array}{c}\text { Coklat } \\
\text { Pekat }\end{array}$ & $\begin{array}{c}\text { Khas Lada } \\
\text { Hitam }\end{array}$ & $\begin{array}{c}\text { Pasta } \\
\text { Kental }\end{array}$
\end{tabular}

GC-MS yang dilakukan dapat dilihat juga bahwa didalam oleoresin yang dihasilkan tidak terkandung sisa alkohol yang digunakan sebagai pelarut. Hasil yang didapat ini sesuai dengan kualitas oleoresin berdasarkan SNI 06-2388-1998 yang menyatakan bahwa kandungan minimum piperin di dalam oleoresin adalah $35 \%$.

Pada penelitian sebelumnya yang dilakukan oleh Dang dan Phan (2014) mengenai ekstraksi lada hitam menggunakan metode $\mathrm{CO}_{2}$ superkritis menghasilkan rendemen sebesar 4,5\% dengan kandungan piperidine sebesar 48,32\%. Kandungan oleoresin yang terdapat di dalam lada hitam dipengaruhi oleh letak geografis, iklim dan cuaca, dan jenis lada hitam.

\subsection{Uji organoleptik pada oleoresin lada hitam}

Hasil uji organoleptik (Tabel 4) yang dilakukan diketahui bahwa kebanyakan koresponden menyatakan oleoresin yang dihasilkan dengan menggunakan metode ultrasonik dan maserasi menghasilkan warna coklat pekat sedangkan oleoresin yang dihasilkan dengan menggunakan metode maserasi menghasilkan warna coklat.

Menurut Kartika (1990), warna atau kenampakan merupakan atribut mata yang ditangkap mata oleh konsumen sebelum penilaian atribut yang lain dari produk. Selain itu, hasil dari sebagian besar kuisioner yang dibagikan kepada panelis juga menunjukkan bahwa aroma oleoresin lada hitam yang dihasilkan dari masingmasing metode memiliki aroma yang sama yaitu aroma khas lada, demikian pula dengan pendapat sebahagian besar koresponden yang menyatakan oleoresin lada hitam berbentuk pasta kental.

\subsection{Perbandingan spesifikasi oleoresin lada hitam SNI 06-2388-1998 dan hasil penelitian \\ Standar oleoresin (SNI 06-2388-1998) menyatakan bahwa oleoresin memiliki warna coklat, dengan bentuk pasta, dan aroma khas}


Tabel 5. Spesifikasi oleoresin lada hitam menurut SNI 06-2388-1998 dan hasil penelitian

\begin{tabular}{|c|c|c|c|}
\hline No & Jenis Uji & SNI & $\begin{array}{c}\text { Hasil } \\
\text { Penelitian }\end{array}$ \\
\hline 1 & $\begin{array}{ll}\text { Kenampakan } \\
\text { - } \quad \text { Warna } \\
\text { - } \quad \text { Bentuk } \\
\text { - Bau }\end{array}$ & $\begin{array}{l}\text { - Coklat } \\
\text { muda,cokl } \\
\text { at pekat } \\
\text { - Pasta cair, } \\
\text { pasta } \\
\text { kental } \\
\text { - Khas lada }\end{array}$ & $\begin{array}{l}\text { - Coklat pekat } \\
\text { - Pasta kental } \\
\text { - Khas lada }\end{array}$ \\
\hline 2 & $\begin{array}{l}\text { Kadar } \\
\text { piperin }\end{array}$ & $\begin{array}{l}\text { Minimal } \\
35,0 \%\end{array}$ & $63,5-69,62 \%$ \\
\hline 3 & $\begin{array}{l}\text { Sisa pelarut } \\
\text { maksimal }\end{array}$ & $\begin{array}{l}\text { Maksimal } \\
\text { sesuai } \\
\text { dengan } \\
\text { peraturan di } \\
\text { Negara } \\
\text { importer }\end{array}$ & 0 \\
\hline
\end{tabular}

lada. Oleoresin dari lada hitam memiliki kandungan piperin lebih besar dari 35\%. Penelitian sebelumnya yang telah dilakukan oleh Singh dkk (2013) mengenai kandungan kimia didalam oleoresin lada (piper ningrum L) menunjukkan bahwa piperine yang terkandung didalam oleoresin adalah sebesar 39\%-63,9\%. Perbandingan antara standar oleoresin yang ada (SNI 06-2388-1998) Dari penelitian yang telah dilakukan, kandungan piperin yang dimiliki oleh oleoresin yang dihasilkan dengan menggunakan metode maserasi sebesar 69,62\%. Dari hasil uji GC-MS yang telah dilakukan dapat dilihat bahwa di dalam oleoresin yang dihasilkan tidak mengandung sisa pelarut $(0 \%)$. Tabel 5 menunjukkan bahwa hasil perbandingan antara standar oleoresin (SNI 06-2388-1998) dengan oleoresin yang dihasilkan dari hasil penelitian menunjukkan bahwa oleoresin yang dihasilkan dengan maserasi memenuhi standar yang ada

\section{Kesimpulan}

Berdasarkan hasil penelitian yang telah dilakukan, diperoleh kesimpulan sebagai berikut:

1. Kondisi optimum ekstraksi oleoresin lada hitam menggunakan Maserasi diperoleh sebesar 4,42\%

2. Kondisi optimum tersebut didapat pada kondisi ekstraksi dengan rasio lada hitam terhadap etanol 99\% 1:4 gr/ml dan waktu ekstraksi 4,68 jam

3. Kandungan piperine yang terdapat pada Oleoresin sebesar sebesar $69,62 \%$

\section{Daftar Pustaka}

Abubakar, Mulyono E, Yulianingsih, 2007. Prospek oleoresin dan penggunaannya di Indonesia. Balai Besar Litbang Pascapanen Pertanian, Bogor.

Anwar C, 1994. Pengantar Praktikum Kimia Organik, Universitas Gajah Mada, Yogyakarta Baranska M and Schulz H, 2009. The Alkaloids. Elsevier, Netherlands

Bagheri H, Mohm yazid, Solati Z, 2014 a. Antioxidant activity of Piper Nigrum L. essensial oil extracted by supercritical $\mathrm{CO}^{2}$ extraction and hydro-distillation. Talanta 121 (2014) 220-228. Doi/org/10.1016/j.talanta. 2014.01.007.

Bambang-Kartika. 1990. Pedoman Uji Inderawi Bahan Pangan. PAU Pangan dan Gizi. Yogyakarta

Dang, Q. T dan Phan, N. N, 2014. Optimization of supercritical $\mathrm{CO}_{2}$ extraction of oleoresin from black pepper (piper nigrum L) and antioxidant capacity of the oleoresin. International Food Research Journal 21 (4): 1489-1493.

Hartuti S, 2011. Optimasi Ekstraksi Oleoresin Jahe dengan menggunakan metode Gelombang Permukaan, Thesis pada Program Pascasarjana Universitas Syiah Kuala.

Kataren S dan Suastawan I.G.M, 1995. Pengaruh Tingkat Mutu Buah Vanili dan Nisbah Bahan dengan pelarut Terhadap Rendeman dan Mutu Oleoresin yang dihasilkan, Jurusan teknologi Industri pertanian, 3: 161-171.

Koswara, 1995. Jahe dan Hasil Pengolahanya. Pustaka Sinar Harapan. Jakarta.

Nuryawan A, Haryati Y, Bandjar H, 2007. Lada (Piper nigrum L) sebagai salah satu Pangan Fungsional Penghasil Devisa. BPTP Bogor

Nurbaiti, Djafar F, Halimah L, 2007. Ekstraksi Komponen Non Volatil Lada Hitam Sebagai Bahan Bumbu. Departemen Perindustrian Badan penelitian dan Pengembangan Industri Balai Riset dan Standardisasi industri Banda Aceh.

Risfaheri, 2012. Diversifikasi Produk Lada (Piper nigrum) untuk Peningkatan Nilai Tambah. 
Buletin Teknologi Pasca panen Pertanian Vol 8 (1). Balai pengkajian Teknologi Pertanaian Kepulauan Bangka Belitung.

Saha K. C, Seal H. P and Noor M. A, 2013. Isolation and characterization of piperine from the fruits of black pepper (piper nigrum). J. Bangladesh Agril, Univ. 11(1): 11-16, 2013 Singh S, Kapoor I. P. S, Singh G, Schuff C. 2013. Chemistry, Antioxidant and Antimicrobial Potentials of white Pepper ( Pipernigrum L) Essensial oil and oleoresins. Proc. Natl. Acad. Sci., Sect. B Biol. Sci. (july-Sept 2013) 83(3):357-336. Doi 10. 1007/s40011-0120148-4

SNI 06-2388-1998, 2007. Oleoresin lada Hitam.

Sulhatun, Jalalluddin dan Tisara, 2014. Lada Hitam sebagai bahan baku Pembuatan Oleoresin dengan Metode Ekstraksi. Jurnal Teknologi Kimia Unimal, Volume 2 Edisi 2 November 2014. Published on Monday, 25 agust 2014. 08.03. 